\title{
Current Evaluation and Management of Excessive Daytime Sleepiness
}

\author{
M.I. Boulos, B.J. Murray
}

\begin{abstract}
Excessive daytime sleepiness has significant impact on neurological function, and has societal implications. Sleepiness is a common feature of many neurological conditions. A careful history will often reveal one of many common causes of excessive daytime sleepiness and suggest appropriate treatment. Neurophysiological testing can provide objective assessment. Behavioural management is an important first step in management. Treatment of common concurrent sleep disorders is also essential. Currently available medications can further symptomatically improve function in many individuals. The strongest evidence base is for the treatment of narcolepsy - a prototype disorder of excessive daytime sleepiness. Currently used medications include modafinil, stimulants, and sodium oxybate amongst others. This review discusses important features in the diagnosis of daytime sleepiness in adults, and outlines a treatment approach. Further evidence-based information about the management of this common problem is essential.
\end{abstract}

RÉSUMÉ: Évaluation et traitement actuel de la somnolence diurne excessive. La somnolence diurne excessive a un impact significatif sur la fonction neurologique et a des conséquences sociétales importantes. La somnolence est une manifestation qui est commune à plusieurs maladies neurologiques. Une histoire médicale minutieuse révélera souvent la présence de l'une de ses nombreuses causes et suggérera le traitement approprié. Des épreuves neurophysiologiques peuvent fournir une évaluation objective. La gestion du comportement constitue la première intervention dans la prise en charge de ces patients. Le traitement des troubles concomitants du sommeil est également important. Les médicaments disponibles actuellement peuvent procurer une amélioration fonctionnelle en réduisant les symptômes chez plusieurs patients. Les données les plus probantes concernent le traitement de la narcolepsie, un prototype de la somnolence diurne excessive. Le modafinil, les stimulants et l'oxybate de sodium sont quelques uns des médicaments utilisés actuellement. Cette revue discute des manifestations de la somnolence diurne qui sont importantes pour son diagnostic chez les adultes et présente une approche de traitement. Il est essentiel d'acquérir de plus amples informations fondées sur des preuves concernant la prise en charge de ce problème fréquent.

Can. J. Neurol. Sci. 2010; 37: 167-176

\section{INTRODUCTION}

\section{A. Scope of the Problem}

Daytime sleepiness is defined by the International Classification of Sleep Disorders, Second Edition as "the inability to stay awake and alert during the major waking episodes of the day, resulting in unintended lapses into drowsiness or sleep"1. Excessive daytime sleepiness (EDS) is one of the most common complaints evaluated by sleep disorder specialists. It has been suggested that one in five people experience significant daytime sleepiness ${ }^{2}$. A Canadian survey showed that $41-42 \%$ of Ontario adolescents reported $\mathrm{EDS}^{3}$.

\section{B. Significance of the Problem}

Excessive daytime sleepiness can result in reduced quality of life for patients, and can overlap clinically with impaired mood and cognitive impairment. Reduced performance becomes of public concern when individuals with EDS are involved in potentially dangerous daily activities such as driving a car.

It has been estimated that $2-4 \%$ of drivers are habitually sleepy while driving ${ }^{4}$ and this affects $24 \%$ of commercial truck drivers ${ }^{5}$. Sleepiness is a recognized cause of traffic accidents that costs our society at least millions of dollars every year ${ }^{6,7}$. There

\footnotetext{
From the Division of Neurology, Department of Medicine, University of Toronto, Sunnybrook Health Sciences Centre, Toronto, Ontario, Canada. Received March 24, 2009. Final Revisions Submitted September 9, 2009. Correspondence to: Brian Murray, Division of Neurology, Department of Medicine, University of Toronto, Sunnybrook Health Sciences Centre, 2075 Bayview Ave Room M1-600, Toronto, Ontario, M4N 3M5, Canada.
} 
are different estimates of the frequency of automobile crashes related to sleepiness: as low as $1-3 \%$ in the United States ${ }^{8}$, but is at least two to ten times as frequent in patients with obstructive sleep apnea compared to controls ${ }^{9}$. Fatigue was thought to be responsible for $10 \%$ of crashes in France ${ }^{10}$. It has been suggested that reductions in road traffic injuries may be achieved if fewer people drive when they are sleep deprived (i.e. have slept for less than five hours during the previous 24 hours) or avoid driving between $2 \mathrm{am}$ and $5 \mathrm{am}^{11}$ - a vulnerable point in the circadian cycle.

Sleep apnea is a common cause of EDS and many studies have demonstrated that patients with this condition have an increased risk of automobile crashes ${ }^{12,13}$ and that this risk can be returned to the population baseline with the use of continuous positive airway pressure ${ }^{9}$.

A full night of sleep deprivation is associated with cognitive impairment comparable to that of being legally intoxicated with alcohol ${ }^{14}$. Pediatric resident performance on simulated driving tasks when post-call during a heavy call rotation is comparable with impairment associated with a 0.04 to $0.05 \mathrm{~g} \%$ blood alcohol concentration $^{15}$. In addition, EDS has been associated with an increased rate of injuries and medical errors in nurses ${ }^{16}$ and resident physician errors ${ }^{17}$. A relationship between EDS and decreased work productivity has also been documented ${ }^{18}$.

The content of this review will focus primarily on adult populations. Further studies in pediatric populations would be warranted given the paucity of literature in this area, the potential contribution of insufficient sleep to attention deficit, and potential implications for developing metabolic syndromes ${ }^{19}$. There is a limited evidence base for the use of medications in many neurological conditions aside from newer medications in the treatment of narcolepsy, refractory sleepiness following treated obstructive apnea and sleepiness associated with circadian sleep disturbances. A recent set of articles has outlined treatment of excessive daytime sleepiness and provided practice suggestions ${ }^{20,21}$, but this article will summarize them, provide an update, and focus on further aspects of practical management.

\section{Important Causes Of Excessive Daytime Sleepiness}

Please see the Table for a list of some common and important causes of excessive daytime sleepiness. A careful clinical history and examination will frequently identify relevant issues.

\section{A. Insufficient Sleep Time}

Sleep deprivation is the most common cause of excessive daytime sleepiness in the general population. Individuals who may be particularly sleepy because of lifestyle include young adults, shift workers, health care professionals, and those in transportation jobs. Among students, psychosocial factors play a major role, including social interactions with friends, extracurricular activities, and early start times for classes. A Canadian study of more than 3000 high school students showed that the majority slept less than 8.5 hours per night and felt "really sleepy" during the beginning of the school day ${ }^{3}$. Patient education is the first step. Similarly, attention to simple measures of good sleep hygiene, such as keeping regular sleep and wake times should be addressed to optimize sleep. Caffeine is commonly used to combat sleepiness, but can be counterproductive when taken close to bed-time. Alcohol is associated with sleep disordered breathing and can aggravate daytime somnolence. Nocturnal insomnia may reduce nocturnal sleep and therefore have daytime consequences.

\section{B. Sleep Apnea}

Many patients who present to a clinician with the complaint of EDS will have obstructive sleep apnea. Obstruction of the upper airway is the most common cause. Symptoms include loud snoring, choking and witnessed pauses in respiration. Physical examination may reveal obesity, increased neck circumference (particularly those 17 inches or greater), and upper airway narrowing. This disorder is a risk factor for hypertension ${ }^{22}$, and stroke $^{23}$. Treatment with continuous positive airway pressure (CPAP) is a first-line treatment option that can help reduce cardiovascular risk ${ }^{24}$. Central sleep apnea is also seen in heart failure most commonly, or with some central nervous system lesions, particularly of the brainstem. Continuous positive airway pressure can be helpful in this condition as well.

\section{C. Narcolepsy}

Narcolepsy is a neurological condition associated with abnormalities of sleep-wake control ${ }^{25}$. Clinical manifestations include prominent daytime sleepiness (which must be present to make the diagnosis), sleep paralysis (waking from sleep unable to move), hypnagogic hallucinations (vivid sensory imagery, usually visual, at sleep onset), and cataplexy (loss of muscle tone during times of increased emotion - most often with laughter) which is virtually pathognomonic for the disorder. These symptoms are thought to represent intrusions of rapid eye movement (REM) sleep phenomena into wakefulness. For example, the atonia of REM sleep may be manifest in the daytime in the form of cataplexy, and hallucinations may represent dreaming associated with REM sleep.

More than $90 \%$ of narcoleptics have a specific HLA haplotype - HLA-DQB $1 * 0602^{26}$. However, this is of limited diagnostic value given that a considerable portion of the general population has this haplotype. Recent developments have implicated a deficiency in signalling by the neurotransmitter system hypocretin, also called orexin ${ }^{27,28}$. Most cases of human narcolepsy with cataplexy have decreased hypocretin in the cerebrospinal fluid ${ }^{29}$. In addition, hypocretin is depleted in narcoleptic brains at autopsy ${ }^{30}$. Therefore, a theory for the pathogenesis of narcolepsy with cataplexy suggests that the condition results from depletion (degeneration or autoimmune attack) of the hypocretin neurons in the posterolateral hypothalamus.

\section{D. Idiopathic Hypersomnia}

This condition is clinically similar to narcolepsy in that EDS occurs despite adequate amounts of apparently normal sleep at night; however, there is no association with cataplexy, and sleep is generally unrefreshing, in contrast to narcolepsy. Sleep drunkenness or inertia is prominent ${ }^{31}$. This condition is a diagnosis of exclusion, and its pathogenesis is unknown. It is likely that this syndromic label represents a number of different abnormalities with a common presentation. Some patients with this disorder have been reported to have Raynaud's phenomenon and autonomic features - this may represent a unique subset. 
Table: Common and important causes of excessive daytime sleepiness (EDS)

\begin{tabular}{|c|c|c|}
\hline Cause of EDS & Clinical history & Treatment \\
\hline $\begin{array}{l}\text { Insufficient sleep } \\
\text { time }\end{array}$ & $\begin{array}{l}\text { - inadequate amount of sleep } \\
\text { - poor sleep "hygiene", such as irregular sleep and wake times } \\
\text { - many forms of insomnia can impair night sleep and have daytime consequences }\end{array}$ & $\begin{array}{l}\text { - increase sleep time } \\
\text { - improve sleep hygiene / education about appropriate } \\
\text { sleep behaviours } \\
\text { - specific therapies based on the type of insomnia may } \\
\text { be used e.g. relaxation techniques etc. }\end{array}$ \\
\hline Sleep apnea & $\begin{array}{l}\text { - loud snoring, gasping or cessation of breathing (apnea) during sleep } \\
\text { - obesity } \\
\text { - upper airway abnormalities } \\
\text { - use of sedatives / alcohol }\end{array}$ & $\begin{array}{l}\text { - weight loss, avoiding sedatives } \\
\text { - positional therapy (i.e. avoid sleeping supine) } \\
\text { - continuous positive airway pressure (CPAP), or bilevel } \\
\text { positive airway pressure (BIPAP) } \\
\text { - dental appliance } \\
\text { - surgery (less commonly) } \\
\text { - after these treatments are implemented, modafinil may } \\
\text { be a useful adjunct }\end{array}$ \\
\hline Narcolepsy & $\begin{array}{l}\text { - must have daytime sleepiness } \\
\text { - cataplexy (loss of muscle tone with emotional stimuli) is pathognomonic } \\
\text { - sleep paralysis } \\
\text { - hypnagogic hallucinations } \\
\text { - fragmented nocturnal sleep }\end{array}$ & $\begin{array}{l}\text { - scheduled naps } \\
\text { - for excessive daytime sleepiness (EDS): modafinil, } \\
\text { stimulants } \\
\text { - for cataplexy: sodium oxybate, tricyclic } \\
\text { antidepressants, selective serotonin reuptake inhibitors } \\
\text { (SSRIs) and venlafaxine }\end{array}$ \\
\hline $\begin{array}{l}\text { Idiopathic } \\
\text { hypersomnia (IH) }\end{array}$ & $\begin{array}{l}\text { - despite adequate sleep time, prominent sleepiness without other rapid eye } \\
\text { movement (REM) sleep related features of narcolepsy } \\
\text { - occasionally associated with Raynaud's phenomenon } \\
\text { - sleep "drunkenness" is a common feature }\end{array}$ & - stimulants and modafinil may be helpful \\
\hline $\begin{array}{l}\text { Recurrent } \\
\text { hypersomnia } \\
\text { (Kleine-Levin } \\
\text { Syndrome) }\end{array}$ & $\begin{array}{l}\text { - more commonly seen in young males } \\
\text { - episodes of severe somnolence that lasts days to weeks, and recurs weeks or } \\
\text { months apart } \\
\text { - cognitive and behavioural disturbances, including confusion, binge eating, } \\
\text { hypersexuality }\end{array}$ & $\begin{array}{l}\text { - lithium may be helpful in reducing attacks } \\
\text { - stimulants and modafinil may be useful in } \\
\text { symptomatic management }\end{array}$ \\
\hline $\begin{array}{l}\text { Circadian Rhythm } \\
\text { Disorders }\end{array}$ & - shift work & $\begin{array}{l}\text { - sensible scheduling practices } \\
\text { - light therapy } \\
\text { - modafinil } \\
\text { - melatonin may be useful in the blind }\end{array}$ \\
\hline $\begin{array}{l}\text { Restless Legs } \\
\text { Syndrome (RLS) } \\
\text { and Periodic Limb } \\
\text { Movement } \\
\text { Disorder (PLMD) }\end{array}$ & $\begin{array}{l}\text { - restless feeling in legs that occurs at rest at night and resolves with movement } \\
\text { - leg jerks or kicking during sleep associated with fragmented sleep } \\
\text { - RLS is often associated with increased arousal but higher doses of dopaminergic } \\
\text { agonists have been associated with sleepiness particularly in Parkinson disease }\end{array}$ & $\begin{array}{l}\text { - address reversible causes e.g. iron deficiency } \\
\text { - minimize high dose dopaminergic agonists } \\
\text { - ensure upper airway resistance is not contributing to } \\
\text { arousals }\end{array}$ \\
\hline $\begin{array}{l}\text { Neurological } \\
\text { conditions }\end{array}$ & $\begin{array}{l}\text { Commonly associated with sleepiness: } \\
\text { - Parkinson disease } \\
\text { - other neurodegenerative disorders } \\
\text { - multiple sclerosis } \\
\text { - stroke } \\
\text { - epilepsy } \\
\text { - neuromuscular disorders } \\
\text { - structural brain disorders: e.g. affecting midline projecting systems, bithalamic, or } \\
\text { bicortical }\end{array}$ & $\begin{array}{l}\text { - management of underlying neurological condition } \\
\text { - stimulants and modafinil may be helpful } \\
\text { - treatment of apnea may be particularly important as } \\
\text { there is an increased incidence in many of these } \\
\text { conditions }\end{array}$ \\
\hline $\begin{array}{l}\text { Medical } \\
\text { conditions }\end{array}$ & $\begin{array}{l}\text { Commonly associated with sleepiness: } \\
\text { - respiratory disorders: e.g. chronic obstructive pulmonary disease (COPD), asthma } \\
\text { - cardiac: congestive heart failure } \\
\text { - renal: chronic renal failure } \\
\text { - rheumatologic: arthritis, inflammatory disorders e.g. lupus } \\
\text { - malignancy } \\
\text { - hepatic: liver failure }\end{array}$ & $\begin{array}{l}\text { - management of underlying medical condition } \\
\text { - avoid use of sedating therapies where possible }\end{array}$ \\
\hline $\begin{array}{l}\text { Psychiatric } \\
\text { Disorders }\end{array}$ & $\begin{array}{l}\text { - mood disorders } \\
\text { - anxiety disorders } \\
\text { - schizophrenia and other psychotic disorders }\end{array}$ & $\begin{array}{l}\text { - management of underlying psychiatric condition } \\
\text { - choice of psychoactive medications that minimize } \\
\text { sedation or preferentially enhances alertness where } \\
\text { possible }\end{array}$ \\
\hline $\begin{array}{l}\text { Medication- } \\
\text { induced } \\
\text { somnolence }\end{array}$ & $\begin{array}{l}\text { - benzodiazepines } \\
\text { - barbiturates } \\
\text { - other "sleeping pills" } \\
\text { - antidepressants } \\
\text { - antipsychotics } \\
\text { - over the counter agents such as antihistamines }\end{array}$ & $\begin{array}{l}\text { - minimize or stop the offending medication where } \\
\text { possible } \\
\text { - appropriately time medications } \\
\text { - institute specific therapies for underlying sleep } \\
\text { disorders }\end{array}$ \\
\hline
\end{tabular}

\section{E. Recurrent Hypersomnia}

Recurrent hypersomnia involves episodes of hypersomnia that last days to weeks, and recur weeks to months apart ${ }^{1}$. Kleine-Levin syndrome, which mainly affects adolescent boys, is characterized by episodic sleep attacks during which the patient sleeps for 16 to 18 hours per day or longer. Other behavioural disturbances during the episodes include hyperphagia, hypersexuality, memory impairment, confusion, and hallucinations ${ }^{32}$. Another form of recurrent hypersomnia: menstrual-related hypersomnia, occurs in association with the menstrual cycle and is often within the first few months after menarche ${ }^{1}$.

\section{F. Circadian Rhythm Disorders}

There are many disorders of circadian rhythms including advances in the sleep phase, delays in the sleep phase, non- 
entrained rhythms and lack of rhythmicity ${ }^{1}$. Patients with shift work or jet lag may have profound somnolence as a normal physiological response to the time of day. Many patients who work shift work also develop a cumulative sleep debt of significance and somnolence is present even when they are on an appropriate schedule. Light therapy may be helpful in establishing optimal circadian patterns and facilitating alertness. Several studies have addressed management with light and melatonin $^{33}$, which is beyond the scope of this review. A particularly important study noted that melatonin may also be useful for improving circadian rhythmicity in blind individuals ${ }^{34}$.

\section{G. Restless Legs Syndrome and Periodic Limb Movement Disorder}

Restless Legs Syndrome (RLS) is characterized by unpleasant leg sensations and an urge to move the legs when at rest. These symptoms are worse towards the end of the day and are relieved with movement. Most patients with RLS have movements of the legs during sleep. Most patient with RLS do not have excessive daytime sleepiness but rather have insomnia. An underlying contributor such as iron deficiency, B12 deficiency, or diabetic neuropathy should be searched for and managed. Treatment with non-ergot dopaminergic agonists such as pramipexole ${ }^{35}$ or ropinirole ${ }^{36}$ can be effective, amongst other options including gabapentin ${ }^{37}$, but the doses should be minimized to avoid sedation associated with these drugs that may be seen in Parkinson disease ${ }^{38}$. Generally, the dose required for treatment of restless legs syndrome is significantly less than that used in Parkinson disease and the medication is taken an hour before bedtime. In Periodic Limb Movement Disorder (PLMD), periodic movements occur during sleep, but the unpleasant sensations are not present. In PLMD, the leg movements occur in the context of EDS or insomnia. It is important to ensure that upper airway resistance is not contributing to limb movements incidentally identified on a polysomnogram. Practically, we often advise treating a patient's sleep disordered breathing (e.g. CPAP for a patient with obstructive sleep apnea (OSA) or upper airway resistance) and then re-evaluating the patient for periodic limb movements.

\section{H. Neurological Disorders Causing Sleepiness}

\section{H1. Parkinson's disease}

Sleep disturbance is a common nonmotor complication of Parkinson disease (PD). Disorders that are often observed during the night in PD include sleep apnea, RLS / PLMD and REM sleep behaviour disorder, which involves patients acting out their dreams as a result of incomplete muscle atonia during REM sleep $^{39}$. As a result of these conditions, and as a function of primary orexin deficiency in the $\mathrm{CNS}^{40}$, EDS is a common occurrence in $\mathrm{PD}^{41}$. Excessive daytime sleepiness may be further exacerbated by the effect of drugs used to treat PD, and by neurodegeneration of central sleep/wake areas ${ }^{42}$.

\section{H2. Other neurodegenerative disorders}

Sleep dysfunction is increasingly recognized in patients with progressive neurodegenerative illnesses, such as Alzheimer's disease, dementia with Lewy bodies, frontotemporal dementia, corticobasal ganglionic degeneration, progressive supranuclear palsy, Huntington's disease, Creutzfeldt-Jakob disease, and fatal familial insomnia ${ }^{43,44}$. The major sleep disturbances in dementing illnesses include hypersomnia, insomnia, circadian rhythm disorders, excessive nocturnal motor activity, "sundowning," and sleep disordered breathing. Sleepiness is particularly common.

\section{H3. Multiple sclerosis (MS)}

The midline projecting systems from the brainstem and base of brain provide adrenergic and cholinergic innervation to the cortex which are essential for wakefulness ${ }^{25}$. As lesions in multiple sclerosis typically affect periventricular areas, the projecting systems of the brainstem are particularly vulnerable. It is therefore not surprising that patients with multiple sclerosis may have somnolence. Fatigue is indeed a common feature of MS, and sleep disorders are likely contributors as well as primary damage to midline projecting systems. Fatigue may encompass other components including pain, disability and impaired mood, but sleep disorders may represent an important treatable contributor. Sleep disturbances in MS are also related to pain, spasticity, sphincter dysfunction, and sleep disordered breathing. Periodic limb movements are very common ${ }^{45}$, likely due to the sensitivity of this syndrome to spinal cord involvement.

\section{H4. Stroke}

Sleep apnea and stroke are closely related. There is an increased frequency of sleep apnea with both infratentorial and supratentorial strokes ${ }^{46}$. Apnea is a risk factor for the development of hypertension and stroke and is important to address for secondary prevention. Obstructive apnea affects up to $60 \%$ of stroke survivors, and is associated with poor outcome in a rehabilitation setting ${ }^{47}$. Diagnosis of apnea may be particularly important for secondary stroke prevention ${ }^{24}$. Further work to assess whether rehabilitation may be improved with treatment of sleepiness is also warranted.

\section{H5. Epilepsy}

The effect of sleep on epilepsy is clear to clinicians. Many seizures are triggered by sleep deprivation. Interictal discharges are also seen more commonly during sleep, especially during non-REM (NREM) sleep, and these can cause repeated arousals and sleep fragmentation resulting in EDS. Epileptic patients demonstrate multiple sleep abnormalities, including increased sleep latency, and fragmented sleep which contributes towards the EDS seen in epileptics ${ }^{48}$. Many patients report somnolence on starting anticonvulsants, perhaps by altering upper airway tone and precipitating sleep disordered breathing. Over 1/3 of refractory epileptic patients have frank obstructive sleep apnea syndrome ${ }^{49}$.

\section{H6. Neuromuscular disease}

Any neuromuscular disease may produce sleep disturbances, including polio, motor neuron disease, polyneuropathy, myasthenia gravis, and myopathies. Sleep disturbances in neuromuscular diseases are generally due to respiratory disturbances related to involvement of the upper airway, respiratory muscles, phrenic and intercostal nerves, or 
neuromuscular junctions of the oropharyngeal and respiratory musculature ${ }^{50}$. A common complaint is EDS resulting from respiratory events that have caused repeated arousals and sleep fragmentation. Myotonic dystrophy is associated with prominent daytime sleepiness ${ }^{51}$ and there may be central mechanisms contributing to this problem. Some central abnormalities have been associated with sleep disturbance in patients with GuillainBarre syndrome ${ }^{52}$. Patients with ALS may have improved survival with treatment of their sleep breathing problems ${ }^{53}$ and improved quality of life.

\section{H7. Structural brain lesions}

Excessive daytime sleepiness can result from tumors and vascular lesions affecting the midline projecting systems, posterior hypothalamus and thalamus ${ }^{54}$. Bithalamic strokes are associated with profound somnolence and bilateral cortical diseases may also impair consciousness. Head injury appears to be associated with decreased orexin levels and this may account for some of the sleep disturbances that are prominent in this condition $^{55}$. Shear forces affecting the relatively midline orexin neurons are likely responsible.

\section{H8. Medical disorders causing sleepiness}

The Table lists several medical conditions that are associated with EDS. When evaluating patients with a complaint of EDS, the clinician should keep in mind the contribution of nonneurological conditions that may play a role in the patient's symptoms. Congestive heart failure, for example, is associated with significant central sleep apnea. Periodic limb movements are common in end-stage renal disease and may even represent a novel predictor of mortality ${ }^{56}$.

\section{H9. Psychiatric disorders and sleepiness}

Potentially any psychiatric disorder, or the medications used to treat these conditions, can disrupt sleep ${ }^{57}$ and some common issues are outlined in the Table. Many of the diagnostic criteria for psychiatric disorders include sleep considerations ${ }^{58}$, such as depression for example. Many psychiatric drugs can affect sleep and medications such as benzodiazepines can induce somnolence for example ${ }^{59}$. Treatment can often be optimized by consideration of chronotherapy - the timing of agents may significantly affect response or side effects. For example, fluoxetine is an alerting antidepressant and is typically administered in the morning where it will not be as disruptive to sleep.

\section{H10. Medication effects}

Excessive daytime sleepiness is a common adverse effect of many medications. Such medications include the benzodiazepines, barbiturates, antidepressants, antipsychotics, opioids, and beta-blockers ${ }^{60}$. Attention to over-the-counter medications must also be considered because common agents such as antihistamines can have substantial effects on daytime alertness. Sleep disorders should be directly treated, rather than masked with a sleeping pill, which often has "hang-over" effects ${ }^{61}$.

\section{Clinical Evaluation Of Daytime Sleepiness}

The most important first step in evaluation of a patient with EDS begins with a detailed history. A sleep-wake diary over several weeks can help identify trends e.g. decreased somnolence with increased sleep time on the weekend, suggesting insufficient sleep is contributing to somnolence during the week. A diary can also highlight interactions between sleep disorders and other neurological conditions e.g. migraine and seizures. Questioning the bed partner is also important as many patients are unaware of their sleep problems. The diagnosis of restless legs syndrome can be made with clinical interview alone. Screening tools for sleep disorders such as the Pittsburgh Sleep Quality Index ${ }^{62}$ and the Sleep Apnea Scale of the Sleep Disorders Questionnaire ${ }^{63}$ may help identify specific sleep disorders and some of these scales have been studied in specific neurological populations such as those with epilepsy ${ }^{64}$. Examination may be less important but reveal important airway factors relevant to sleep apnea. Signs of systemic disease may be elicited and nervous system examination may reveal features suggesting a structural brain abnormality or neuromuscular features that might impair airway control or be associated with restless legs syndrome and limb movements in sleep ${ }^{65}$. If the cause of somnolence is not obvious or obviously treated, polysomnography and alertness testing may be considered.

\section{Measurements Of Daytime Sleepiness}

\section{A. Commonly Used Subjective Measures}

\section{A1. Epworth sleepiness scale}

The Epworth Sleepiness Scale (ESS) is a self-administered questionnaire that provides a measure of subjective daytime sleepiness. Subjects are asked to rate the chances that they would doze off or fall asleep when in eight situations encountered in routine daily life. Each item is scored by the patient from 0 (never) to 3 (high chance), with a total that can range from 0 to $24^{66}$.

Criticism has been levelled against the ESS, including validity data, and the lack of reliability in patients with significant sleepiness ${ }^{67,68}$. In addition, studies that suggested the ESS correlated with mean sleep latency on the objective Multiple Sleep Latency Test (MSLT) and with severity of sleep apnea demonstrated associations that were not particularly strong or consistent ${ }^{69}$. It has been suggested that the ESS, and MSLT, may tap into confounds such as motivation. Patients are often poor at self-report of their alertness state, and may also falsely report their level of alertness in order to preserve their driving status for example. Nonetheless, this is a widely used scale and is one of the best tools available for assessment of subjective sleepiness.

\section{A2. Stanford sleepiness scale (SSS)}

In the $\mathrm{SSS}^{70}$, the subject must choose from descriptions of different sleepiness levels (from fully awake to fully asleep) that best defines their current state. One problem with this scale is that it gives one only an instant picture of the sleepiness of the patient, which may vary widely moment to moment.

\section{B. Objective Measures}

Polysomnography (a "many sleep graph", or a routine sleep study) is sometimes obtained to rule out an intrinsic sleep disorder such as obstructive sleep apnea. Physiological parameters that are typically collected include a limited EEG 
montage, electrooculogram, surface EMG, ECG, respiratory channels, and oxygen saturation ${ }^{71}$.

\section{B1. Multiple sleep latency test}

The Multiple Sleep Latency Test is preceded by nocturnal polysomnography, and consists of sleep monitoring during four or five naps spread over the course of a day at two hour intervals. The patient is asked to attempt to fall asleep and is given 20 minutes to do so. Once sleep is attained, the patient is given another 15 minutes to see if they reach REM sleep. After nap termination, the patient is instructed to get out of bed and remain awake until the next nap opportunity. The sleep latency (time from lights out until the beginning of sleep) and the presence of REM are determined for each nap ${ }^{72,73}$.

The normal MSLT typically shows a mean sleep latency (MSL) longer than 12 minutes and with zero to one REM periods in the naps. It has traditionally been thought that a MSL of less than ten minutes is abnormal, with five to ten minutes representing moderate sleepiness and less than five minutes signifying severe sleepiness. However, medical judgment rather than absolute values or test scores must weigh significantly in the interpretation ${ }^{74}$. The test is usually abnormal in patients with clear narcolepsy with cataplexy, and this remains the goldstandard for diagnosis of this condition.

\section{B2. Maintenance of wakefulness test}

The Maintenance of Wakefulness Test (MWT) was designed to test a patient's ability to stay awake and has better surface validity for the assessment of alertness in the day. The patient is seated upright in bed or in a chair in a dimly lighted room and asked to remain awake for either 20 or 40 minutes. The test is terminated if sleep is noted. The test is repeated four or five times during the day, two hours apart, and the MSL is determined ${ }^{73}$. Never falling asleep in any of the four trials of a MWT is the strongest objective evidence of an individual's ability to stay awake but, as with the MSLT, MWT test results are most valuable when integrated with the clinical history and carefully interpreted.

The MSLT and MWT are the gold standard tools available for the assessment of alertness, but cheaper, easier to administer, and better validated tests are required. In particular, assessment of the MWT in relation to accidents in the "real world" would be very helpful.

\section{B3. Psychomotor vigilance test}

Sleepiness compromises the ability of individuals to respond to stimuli quickly. Deficits have been attributed to failures in vigilant attention. One of the leading paradigms used to test vigilant attention is the Psychomotor Vigilance Test, a reactiontime test that is sensitive to sleep deprivation and circadian rhythms. Sleep deprivation results in an overall slowing of responses. Sleep deprivation also increases the propensity of individuals to lapse for lengthy periods ( $>500 \mathrm{~ms}$ response times). Psychomotor vigilance testing results during extended periods of wakefulness reveal the presence of interacting circadian and homeostatic factors ${ }^{75}$. Research has shown there are marked increases in Psychomotor Vigilance Test performance variability as sleep loss continues ${ }^{76}$. The test is easy to perform in clinical populations, but is hampered by the fact that there must be a motor response, which presents difficulties in use in patients with motor impairments e.g. stroke, and Parkinson disease.

\section{Treatment OPtions}

An accurate diagnosis of the underlying sleep disorder must be made and other contributing causes ruled out. Management of the primary or coexistent disorders may require specific therapeutic interventions aside from the non-pharmacological approaches and pharmacological agents described here.

\section{A. Non-Pharmacological Therapy}

\section{A1. Insufficient sleep time and basic sleep hygiene}

Patients should be encouraged to improve their sleep hygiene and increase their sleep time. Aspects of good sleep hygiene include regular sleep and wake times, avoiding the consumption of tobacco, caffeinated beverages or alcohol close to bedtime, avoidance of daytime naps, use of the bed for sleep and sex only, and to keep the bedroom dark, quiet and cool. Various forms of insomnia may be amenable to specific behavioural interventions including relaxation techniques and cognitive behavioural therapy ${ }^{77}$, which will help avoid the use of sedating sleeping pills with potential adverse carryover effects into the daytime.

\section{A2. Scheduled naps}

Scheduled naps can be beneficial to combat sleepiness but seldom suffice as primary therapy for conditions such as narcolepsy. The combination of regular bedtimes and two 15minute regularly scheduled naps reduced unscheduled daytime sleep episodes and sleepiness ${ }^{78}$.

\section{A3. Sleep apnea}

Treatment of OSA is guided by disease severity noted on polysomnography. Mild OSA may be successfully treated with weight loss, or using positional therapy, such as instructing the patient to place a tennis ball in a shirt pocket and then wear the shirt backwards during sleep; the goal of this simple strategy is to avoid having the patient sleep in the supine position. Moderate to severe cases of OSA may require the use of a dental appliance to advance the tongue or mandible and improve airway patency, CPAP to splint the airway open, or bi-level positive airway pressure (BIPAP). Continuous positive airway pressure is a firstline therapy, and patients need to have careful attention paid to establishing an optimal pressure setting as well as an appropriate mask interface. Patients with bulbar control problems may be required to use a less comfortable full-face mask in contrast to a nasal interface. The technology continues to improve, and patients that couldn't tolerate the machines even ten years ago now find the quieter, simpler, more comfortable masks and machines acceptable. Bi-level positive airway pressure provides different pressures during inspiration and expiration, and may be particularly useful in selected cases, such as patients with neuromuscular diseases affecting the respiratory musculature (e.g. ALS, myotonic dystrophy, etc.). A backup respiratory rate can be provided. Upper airway surgery is a treatment consideration for patients who have failed or cannot tolerate other forms of therapy. Surgery aims to reduce anatomical upper 
airway obstruction. Successful surgery depends on proper patient selection, proper procedure selection, and experience of the surgeon $^{79}$. More advanced surgery may be required in severe cases or in situations where there are craniofacial deformities.

\section{A4. Treatment of other sleep disorders}

Having the patients reduce sedative medication may be particularly helpful. Attention to the timing of sedating medication (chronotherapy) may also have significant advantages. Treatment of other sleep disorders will be helpful and be specific to the situation. Restless legs syndrome, for example, is sometimes associated with iron deficiency and supplementation represents a good option where appropriate. For others, dopaminergic agents may be required, but the dose should be kept as low as possible to minimize the possibility of iatrogenic sedation.

\section{B. Pharmacological Therapy}

\section{B1. Modafinil and armodafinil}

Modafinil is effective for the treatment of daytime sleepiness in narcolepsy. In two double-blind, placebo-controlled trials, modafinil at doses of $200 \mathrm{mg}$ and $400 \mathrm{mg}$ was shown to enhance wakefulness $^{80,81}$. Three studies have shown that multiple dose regimens provide better control of sleepiness than a single daily dose $^{82-84}$. For this reason, the medication is often started at 100 $\mathrm{mg}$ in the morning, and another $100 \mathrm{mg}$ is added in the afternoon, and doses are increased at those times.

One open label study showed modafinil improved alertness in 13 children (mean age 11 years) with narcolepsy or idiopathic hypersomnia $^{85}$. In December 2007, however, Health Canada issued a warning regarding modafinil. In adults and children using modafinil, rare cases of Toxic Epidermal Necrolysis, Stevens-Johnson syndrome, and other serious hypersensitivity reactions were reported above the background incidence rate in the general population. Patients should be warned of the possibility, though the risk seemed most evident in children. Modafinil should be discontinued at the first sign of rash unless the rash is clearly not drug-related. The product monograph was updated to state that modafinil is not approved for use in pediatric patients for any indication. The same Health Canada warning reported that modafinil can cause or exacerbate psychiatric symptoms though is generally well tolerated aside from headache.

Modafinil may be useful for the treatment of idiopathic hypersomnia. One study found decreases in the number of drowsy episodes and sleep episodes for patients on this drug ${ }^{86}$. Others have noted responses in observational nonrandomized studies $^{31}$.

This medication may be effective for treatment of daytime sleepiness due to Parkinson's disease, but the available data is limited. One randomized controlled trial showed improvement in the $\mathrm{ESS}^{87}$, and a further study also showed improvement ${ }^{88}$. Another study showed no improvement in subjective or objective measures $^{89}$.

Modafinil may be helpful for treatment of daytime sleepiness due to myotonic dystrophy. One small randomized controlled study showed improvement in MWT but no significant change in $\mathrm{ESS}^{90}$.
Based on two studies that demonstrated effectiveness in improving the Epworth Sleepiness Scale, modafinil may be effective for treatment of daytime sleepiness due to multiple sclerosis $^{91,92}$. However no objective measures of sleepiness have been obtained.

Modafinil has been used as an adjunctive therapy for refractory sleepiness following sleep apnea treatment with $\mathrm{CPAP}^{93}$ and for sleepiness associated with circadian rhythm sleep disturbances ${ }^{94}$.

Modafinil is not thought to affect blood pressure or heart rate at standard doses.

A randomized controlled study assessed armodafinil (the longer half-life enantiomer of modafinil) for the treatment of EDS in patients with narcolepsy. Subjects receiving armodafinil experienced significant improvement in sleepiness as measured by the MWT $^{95}$. This medication is not currently available in Canada.

\section{B2. Sodium oxybate}

Sodium oxybate is an effective treatment for cataplexy, disrupted sleep, and sleepiness in narcolepsy. Studies have shown improvements in subjective and objective measures of sleepiness.

Three randomized controlled studies demonstrated treatment effects for cataplexy ${ }^{96-98}$. One of the studies also noted efficacy in managing sleepiness ${ }^{96}$. Two other randomized controlled studies demonstrated improved alertness ${ }^{99,100}$.

Other studies with lower levels of evidence supported its efficacy in improving daytime sleepiness, and reducing nocturnal awakenings ${ }^{101}$ as well as demonstrating efficacy for cataplexy and daytime sleepiness ${ }^{102}$. There may be an additive effect of the combination of modafinil and sodium oxybate in improving sleepiness compared to modafinil alone ${ }^{99}$.

This drug is administered under careful observation given the potential for abuse of the medication as a "date-rape" agent. This is particularly unfortunate given its particular benefit to patients with refractory cataplexy. The medication is fast acting and has a short half life. Patients are therefore counselled to take the medication in bed to prevent a fall en route from the bathroom, and they will take a second dose a few hours after falling asleep after awakening spontaneously or with the assistance of an alarm clock.

\section{B3. Stimulants}

Amphetamine, methamphetamine, dextroamphetamine, and methylphenidate appear to be useful for the treatment of daytime sleepiness in narcolepsy. These medications have been used for a long time, but there is limited information in the form of randomized controlled trials. Pemoline has been removed from the market due to hepatic failure and is no longer recommended. The same medications are sometimes used for the treatment of recurrent hypersomnia, idiopathic hypersomnia, and hypersomnia due to medical conditions. While limited data exists to support the use of these medications in these conditions, a recent expert consensus review stated that "there is no reason to suspect they will not improve alertness", and cautioned that "individualized therapy and close follow-up to ensure efficacy and monitor for side effects is needed" 20 . 
Methylphenidate may be useful for treatment of sleepiness due to myotonic dystrophy. One small study of methylphenidate demonstrated improvement in subjective sleepiness in 7 of 11 subjects at doses up to $40 \mathrm{mg} /$ day $^{103}$.

Some patients have a tendency to respond to one agent preferentially over another. Long acting forms and short acting forms can be combined to find an effective regimen for the patient based on their clinical needs. Typically we start with slow release methylphenidate $20 \mathrm{mg}$ in the morning and add short acting agents in $5 \mathrm{mg}$ doses in the afternoon where needed. Patients may also have idiosyncratic anxiety responses. Patients are counselled to keep the dose consistent, and not adjust without consultation with their treating physician, in order to reduce abuse potential. Blood pressure needs to be monitored carefully.

\section{B4. Antidepressants}

Antidepressant agents such as tricyclics, and selective serotonin reuptake inhibitors may be effective treatments for cataplexy, and other features of narcolepsy. Most of the evidence behind these agents comes from case reports and small studies and have been recommended on the basis of committee consensus for the treatment of cataplexy ${ }^{20}$. Minimizing or reducing sedating tricyclics (e.g. amitriptyline or clomipramine) may avoid daytime sedation. Some medications such as fluoxetine are relatively alerting and disruptive to nocturnal sleep, so they are preferentially given in the morning. Antidepressant medications can aggravate motor symptoms in sleep including periodic limb movements and REM sleep behaviour disorder.

\section{B5. Lithium carbonate}

A non-controlled case series of five patients suggested that the duration of hypersomnia episodes was shorter in KleineLevin syndrome patients treated with lithium carbonate ${ }^{104}$. This disorder is rare, so it is doubtful large studies will be arranged to formally assess this agent in this condition.

\section{C. New Drugs Under Development}

The relatively recent discovery of the neuropeptide orexin/hypocretin and its involvement in narcolepsy has revolutionized our understanding of the basic control of sleep and wakefulness. New drug targets based on these observations will hopefully lead to new agents that may be beneficial in humans. Recent studies have suggested that inhaled orexin could improve alertness in primates for example ${ }^{105}$.

\section{Conclusions}

Excessive daytime sleepiness is an important clinical and public health issue. Identification of this problem can lead to rational treatment interventions that will benefit many neurological patients. Adding a sleep history to assessments will help clinicians identify many common, serious, yet easily treatable sleep disorders. While many medications for daytime sleepiness are available and appear to be useful and generally safe, the evidence base is limited as many of the agents have not been formally studied and are unlikely to be subjected to the same scrutiny as new pharmacologic agents. Nonetheless there are many clinical treatment options, and simple interventions can often make a huge impact in a patient's quality of life. As further studies emerge, we are likely to be impressed by the impact of treating sleepiness in neurological patient populations. Furthermore, the rapid advances in the neurobiology of sleep will likely lead to new specific treatment options shortly. Increased awareness of excessive daytime sleepiness in our patients, as well as advances in our understanding of the neurophysiology of sleepiness will help identify important rehabilitation targets for many neurological conditions, and therefore warrants our clinical attention.

\section{REFERENCES}

1. American Academy of Sleep Medicine. The international classification of sleep disorders: diagnostic and coding manual. 2nd ed. Westchester, Ill.: American Academy of Sleep Medicine; 2005.

2. Young TB. Epidemiology of daytime sleepiness: definitions, symptomatology, and prevalence. J Clin Psychiatry. 2004;65 Suppl 16:12-6.

3. Gibson ES, Powles AC, Thabane L, O'Brien S, Molnar DS, Trajanovic N, et al. "Sleepiness" is serious in adolescence: two surveys of 3235 Canadian students. BMC Public Health. 2006;6:116.

4. Masa JF, Rubio M, Findley LJ. Habitually sleepy drivers have a high frequency of automobile crashes associated with respiratory disorders during sleep. Am J Respir Crit Care Med. 2000 Oct; 162(4 Pt 1):1407-12.

5. Howard ME, Desai AV, Grunstein RR, Hukins C, Armstrong JG, Joffe D, et al. Sleepiness, sleep-disordered breathing, and accident risk factors in commercial vehicle drivers. Am J Respir Crit Care Med. 2004 Nov 1;170(9):1014-21.

6. Leger D. The cost of sleep-related accidents: a report for the National Commission on Sleep Disorders Research. Sleep. 1994 Feb;17(1):84-93.

7. Webb WB. The cost of sleep-related accidents: a reanalysis. Sleep. 1995 May;18(4):276-80.

8. Lyznicki JM, Doege TC, Davis RM, Williams MA. Sleepiness, driving, and motor vehicle crashes. Council on Scientific Affairs, American Medical Association. JAMA. 1998 Jun 17;279(23): 1908-13.

9. George CF. Sleep apnea, alertness, and motor vehicle crashes. Am J Respir Crit Care Med. 2007 Nov 15;176(10):954-6.

10. Philip P, Vervialle F, Le Breton P, Taillard J, Horne JA. Fatigue, alcohol, and serious road crashes in France: factorial study of national data. BMJ. 2001 Apr 7;322(7290):829-30.

11. Connor J, Norton R, Ameratunga S, Robinson E, Civil I, Dunn R, et al. Driver sleepiness and risk of serious injury to car occupants: population based case control study. BMJ. 2002 May 11;324 (7346): 1125 .

12. Young T, Blustein J, Finn L, Palta M. Sleep-disordered breathing and motor vehicle accidents in a population-based sample of employed adults. Sleep. 1997 Aug;20(8):608-13.

13. Krieger J, Meslier N, Lebrun T, Levy P, Phillip-Joet F, Sailly JC, et al. Accidents in obstructive sleep apnea patients treated with nasal continuous positive airway pressure: a prospective study. The Working Group ANTADIR, Paris and CRESGE, Lille, France. Association Nationale de Traitement a Domicile des Insuffisants Respiratoires. Chest. 1997 Dec;112(6):1561-6.

14. Dawson D, Reid K. Fatigue, alcohol and performance impairment. Nature. 1997 Jul 17;388(6639):235.

15. Arnedt JT, Owens J, Crouch M, Stahl J, Carskadon MA. Neurobehavioral performance of residents after heavy night call vs after alcohol ingestion. JAMA. 2005 Sep 7;294(9):1025-33.

16. Suzuki K, Ohida T, Kaneita Y, Yokoyama E, Uchiyama M. Daytime sleepiness, sleep habits and occupational accidents among hospital nurses. J Adv Nurs. 2005 Nov;52(4):445-53.

17. Landrigan CP, Rothschild JM, Cronin JW, Kaushal R, Burdick E, Katz JT, et al. Effect of reducing interns' work hours on serious medical errors in intensive care units. N Engl J Med. 2004 Oct 28;351(18):1838-48. 
18. Mulgrew AT, Ryan CF, Fleetham JA, Cheema R, Fox N, Koehoorn $\mathrm{M}$, et al. The impact of obstructive sleep apnea and daytime sleepiness on work limitation. Sleep Med. 2007 Dec;9(1):42-53.

19. Reilly JJ, Armstrong J, Dorosty AR, Emmett PM, Ness A, Rogers I, et al. Early life risk factors for obesity in childhood: cohort study. BMJ. 2005 Jun 11;330(7504):1357.

20. Morgenthaler TI, Kapur VK, Brown T, Swick TJ, Alessi C, Aurora $\mathrm{RN}$, et al. Practice parameters for the treatment of narcolepsy and other hypersomnias of central origin. Sleep. 2007 Dec 1;30 (12):1705-11

21. Wise MS, Arand DL, Auger RR, Brooks SN, Watson NF. Treatment of narcolepsy and other hypersomnias of central origin. Sleep. 2007 Dec 1;30(12):1712-27.

22. Peppard PE, Young T, Palta M, Skatrud J. Prospective study of the association between sleep-disordered breathing and hypertension. N Engl J Med. 2000 May 11;342(19):1378-84.

23. Yaggi HK, Concato J, Kernan WN, Lichtman JH, Brass LM, Mohsenin V. Obstructive sleep apnea as a risk factor for stroke and death. N Engl J Med. 2005 Nov 10;353(19):2034-41.

24. Marin JM, Carrizo SJ, Vicente E, Agusti AG. Long-term cardiovascular outcomes in men with obstructive sleep apnoeahypopnoea with or without treatment with continuous positive airway pressure: an observational study. Lancet. 2005 Mar 1925;365(9464): 1046-53.

25. Scammell TE. The neurobiology, diagnosis, and treatment of narcolepsy. Ann Neurol. 2003 Feb;53(2):154-66.

26. Mignot E, Lin X, Arrigoni J, Macaubas C, Olive F, Hallmayer J, et al. DQB1*0602 and DQA1*0102 (DQ1) are better markers than DR2 for narcolepsy in Caucasian and black Americans. Sleep. 1994 Dec;17 Suppl 8:S60-7.

27. Chemelli RM, Willie JT, Sinton CM, Elmquist JK, Scammell T, Lee $\mathrm{C}$, et al. Narcolepsy in orexin knockout mice: molecular genetics of sleep regulation. Cell. 1999 Aug 20;98(4):437-51.

28. Lin L, Faraco J, Li R, Kadotani H, Rogers W, Lin X, et al. The sleep disorder canine narcolepsy is caused by a mutation in the hypocretin (orexin) receptor 2 gene. Cell. 1999 Aug 6;98(3): 365-76.

29. Nishino S. Clinical and neurobiological aspects of narcolepsy. Sleep Med. 2007 Jun;8(4):373-99.

30. Thannickal TC, Moore RY, Nienhuis R, Ramanathan L, Gulyani S, Aldrich $\mathrm{M}$, et al. Reduced number of hypocretin neurons in human narcolepsy. Neuron. 2000 Sep;27(3):469-74.

31. Anderson KN, Pilsworth S, Sharples LD, Smith IE, Shneerson JM. Idiopathic hypersomnia: a study of 77 cases. Sleep. 2007 Oct 1; 30(10): 1274-81.

32. Arnulf I, Lin L, Gadoth N, File J, Lecendreux M, Franco P, et al. Kleine-Levin syndrome: a systematic study of 108 patients. Ann Neurol. 2008 Apr;63(4):482-93.

33. Morgenthaler TI, Lee-Chiong T, Alessi C, Friedman L, Aurora RN, Boehlecke B, et al. Practice parameters for the clinical evaluation and treatment of circadian rhythm sleep disorders. An American Academy of Sleep Medicine report. Sleep. 2007 Nov $1 ; 30(11): 1445-59$

34. Sack RL, Brandes RW, Kendall AR, Lewy AJ. Entrainment of freerunning circadian rhythms by melatonin in blind people. $\mathrm{N}$ Engl J Med. 2000 Oct 12;343(15):1070-7.

35. Winkelman JW, Sethi KD, Kushida CA, Becker PM, Koester J, Cappola JJ, et al. Efficacy and safety of pramipexole in restless legs syndrome. Neurology. 2006 Sep 26;67(6):1034-9.

36. Quilici S, Abrams KR, Nicolas A, Martin M, Petit C, Lleu PL, et al. Meta-analysis of the efficacy and tolerability of pramipexole versus ropinirole in the treatment of restless legs syndrome. Sleep Med. 2008 Oct;9(7):715-26.

37. Trenkwalder C, Hening WA, Montagna P, Oertel WH, Allen RP, Walters AS, et al. Treatment of restless legs syndrome: an evidence-based review and implications for clinical practice. Mov Disord. 2008 Dec 15;23(16):2267-302.

38. Paus S, Brecht HM, Koster J, Seeger G, Klockgether T, Wullner U. Sleep attacks, daytime sleepiness, and dopamine agonists in Parkinson's disease. Mov Disord. 2003 Jun;18(6):659-67.

39. Schenck CH, Mahowald MW. REM sleep behavior disorder: clinical, developmental, and neuroscience perspectives 16 years after its formal identification in SLEEP. Sleep. 2002 Mar 15;25 (2): $120-38$.

40. Thannickal TC, Lai YY, Siegel JM. Hypocretin (orexin) cell loss in Parkinson's disease. Brain. 2007 Jun;130(Pt 6):1586-95.

41. Hobson DE, Lang AE, Martin WR, Razmy A, Rivest J, Fleming J. Excessive daytime sleepiness and sudden-onset sleep in Parkinson disease: a survey by the Canadian Movement Disorders Group. JAMA. 2002 Jan 23-30;287(4):455-63.

42. Comella CL. Sleep disturbances and excessive daytime sleepiness in Parkinson disease: an overview. J Neural Transm Suppl. 2006 (70):349-55.

43. Bhatt MH, Podder N, Chokroverty S. Sleep and neurodegenerative diseases. Semin Neurol. 2005 Mar;25(1):39-51.

44. McCurry SM, Ancoli-Israel S. Sleep dysfunction in Alzheimer's disease and other dementias. Curr Treat Options Neurol. 2003 May;5(3):261-72.

45. Auger C, Montplaisir J, Duquette P. Increased frequency of restless legs syndrome in a French-Canadian population with multiple sclerosis. Neurology. 2005 Nov 22;65(10):1652-3

46. Bassetti CL. Sleep and stroke. Semin Neurol. 2005 Mar;25(1): 19-32.

47. Kaneko Y, Hajek VE, Zivanovic V, Raboud J, Bradley TD. Relationship of sleep apnea to functional capacity and length of hospitalization following stroke. Sleep. 2003 May 1;26(3): 293-7.

48. Mendez M, Radtke RA. Interactions between sleep and epilepsy. J Clin Neurophysiol. 2001 Mar;18(2):106-27.

49. Malow BA, Levy K, Maturen K, Bowes R. Obstructive sleep apnea is common in medically refractory epilepsy patients. Neurology. 2000 Oct 10;55(7):1002-7.

50. Guilleminault C, Shergill RP. Sleep-disordered breathing in neuromuscular disease. Curr Treat Options Neurol. 2002 Mar;4 (2):107-12.

51. Laberge L, Begin P, Dauvilliers Y, Beaudry M, Laforte M, Jean S, et al. A polysomnographic study of daytime sleepiness in myotonic dystrophy type 1. J Neurol Neurosurg Psychiatry. 2009 Jun;80(6)642-6.

52. Cochen V, Arnulf I, Demeret S, Neulat ML, Gourlet V, Drouot X, et al. Vivid dreams, hallucinations, psychosis and REM sleep in Guillain-Barre syndrome. Brain. 2005 Nov;128(Pt 11):2535-45.

53. Kleopa KA, Sherman M, Neal B, Romano GJ, Heiman-Patterson T. Bipap improves survival and rate of pulmonary function decline in patients with ALS. J Neurol Sci. 1999 Mar 15;164(1):82-8.

54. Saper CB, Chou TC, Scammell TE. The sleep switch: hypothalamic control of sleep and wakefulness. Trends Neurosci. 2001 Dec;24 (12):726-31.

55. Baumann CR, Stocker R, Imhof HG, Trentz O, Hersberger M, Mignot E, et al. Hypocretin-1 (orexin A) deficiency in acute traumatic brain injury. Neurology. 2005 Jul 12;65(1):147-9.

56. Benz RL, Pressman MR, Hovick ET, Peterson DD. Potential novel predictors of mortality in end-stage renal disease patients with sleep disorders. Am J Kidney Dis. 2000 Jun;35(6):1052-60.

57. Doghramji K, editor. The sleep-psychiatry interface. Philadelphia: Elsevier; 2006

58. American Psychiatric Association. Task Force on DSM-IV. Diagnostic and statistical manual of mental disorders: DSM-IVTR. 4th ed. Washington, DC: American Psychiatric Association; 2000

59. Rapoport MJ, Lanctot KL, Streiner DL, Bedard M, Vingilis E, Murray B, et al. Benzodiazepine use and driving: a metaanalysis. J Clin Psychiatry. 2009 May;70(5):663-73.

60. Roth T, Roehrs TA. Etiologies and sequelae of excessive daytime sleepiness. Clin Ther. 1996 Jul-Aug;18(4):562-76; discussion 1.

61. Vermeeren A. Residual effects of hypnotics: epidemiology and clinical implications. CNS Drugs. 2004;18(5):297-328.

62. Buysse DJ, Reynolds CF, 3rd, Monk TH, Berman SR, Kupfer DJ. The Pittsburgh Sleep Quality Index: a new instrument for psychiatric practice and research. Psychiatry Res. 1989 May;28(2):193-213.

63. Douglass AB, Bornstein R, Nino-Murcia G, Keenan S, Miles L, Zarcone VP, Jr., et al. The Sleep Disorders Questionnaire. I: Creation and multivariate structure of SDQ. Sleep. 1994 Mar;17 (2):160-7. 
64. Weatherwax KJ, Lin X, Marzec ML, Malow BA. Obstructive sleep apnea in epilepsy patients: the Sleep Apnea scale of the Sleep Disorders Questionnaire (SA-SDQ) is a useful screening instrument for obstructive sleep apnea in a disease-specific population. Sleep Med. 2003 Nov;4(6):517-21.

65. Hattan E, Chalk C, Postuma RB. Is there a higher risk of restless legs syndrome in peripheral neuropathy? Neurology. 2009 Mar 17;72(11):955-60

66. Johns MW. A new method for measuring daytime sleepiness: the Epworth sleepiness scale. Sleep. 1991 Dec;14(6):540-5.

67. Miletin MS, Hanly PJ. Measurement properties of the Epworth sleepiness scale. Sleep Med. 2003 May;4(3):195-9.

68. Chervin RD. Epworth sleepiness scale? Sleep Med. 2003 May;4(3): $175-6$.

69. Chervin RD, Aldrich MS. The Epworth Sleepiness Scale may not reflect objective measures of sleepiness or sleep apnea. Neurology. 1999 Jan 1;52(1):125-31

70. Hoddes E, Zarcone V, Smythe H, Phillips R, Dement WC. Quantification of sleepiness: a new approach. Psychophysiology. 1973 Jul;10(4):431-6.

71. Iber C, American Academy of Sleep Medicine. The AASM manual for the scoring of sleep and associated events: rules, terminology and technical specifications. Westchester, IL: American Academy of Sleep Medicine; 2007.

72. Carskadon MA, Dement WC, Mitler MM, Roth T, Westbrook PR, Keenan S. Guidelines for the multiple sleep latency test (MSLT): a standard measure of sleepiness. Sleep. 1986 Dec;9(4):519-24.

73. Littner MR, Kushida C, Wise M, Davila DG, Morgenthaler T, LeeChiong $\mathrm{T}$, et al. Practice parameters for clinical use of the multiple sleep latency test and the maintenance of wakefulness test. Sleep. 2005 Jan 1;28(1):113-21.

74. Wise MS. Objective measures of sleepiness and wakefulness: application to the real world? J Clin Neurophysiol. 2006 Feb;23 (1):39-49

75. Lim J, Dinges DF. Sleep deprivation and vigilant attention. Ann N Y Acad Sci. 2008;1129:305-22.

76. Doran SM, Van Dongen HP, Dinges DF. Sustained attention performance during sleep deprivation: evidence of state instability. Arch Ital Biol. 2001 Apr;139(3):253-67.

77. Baillargeon L, Landreville P, Verreault R, Beauchemin JP, Gregoire JP, Morin CM. Discontinuation of benzodiazepines among older insomniac adults treated with cognitive-behavioural therapy combined with gradual tapering: a randomized trial. CMAJ. 2003 Nov 11;169(10):1015-20.

78. Rogers AE, Aldrich MS, Lin X. A comparison of three different sleep schedules for reducing daytime sleepiness in narcolepsy. Sleep. 2001 Jun 15;24(4):385-91.

79. Won CH, Li KK, Guilleminault C. Surgical treatment of obstructive sleep apnea: upper airway and maxillomandibular surgery. Proc Am Thorac Soc. 2008 Feb 15;5(2):193-9.

80. US Modafinil in Narcolepsy Multicenter Study Group. Randomized trial of modafinil for the treatment of pathological somnolence in narcolepsy. Ann Neurol. 1998 Jan;43(1):88-97.

81. US Modafinil in Narcolepsy Multicenter Study Group. Randomized trial of modafinil as a treatment for the excessive daytime somnolence of narcolepsy: Neurology. 2000 Mar 14;54(5): 1166-75.

82. Schwartz JR, Feldman NT, Bogan RK, Nelson MT, Hughes RJ. Dosing regimen effects of modafinil for improving daytime wakefulness in patients with narcolepsy. Clin Neuropharmacol. 2003 Sep-Oct;26(5):252-7.

83. Schwartz JR, Nelson MT, Schwartz ER, Hughes RJ. Effects of modafinil on wakefulness and executive function in patients with narcolepsy experiencing late-day sleepiness. Clin Neuropharmacol. 2004 Mar-Apr;27(2):74-9.

84. Schwartz JR, Feldman NT, Bogan RK. Dose effects of modafinil in sustaining wakefulness in narcolepsy patients with residual evening sleepiness. J Neuropsychiatry Clin Neurosci. 2005 Summer;17(3):405-12.

85. Ivanenko A, Tauman R, Gozal D. Modafinil in the treatment of excessive daytime sleepiness in children. Sleep Med. 2003 Nov; 4(6):579-82.
86. Bastuji H, Jouvet M. Successful treatment of idiopathic hypersomnia and narcolepsy with modafinil. Prog Neuropsychopharmacol Biol Psychiatry. 1988;12(5):695-700.

87. Hogl B, Saletu M, Brandauer E, Glatzl S, Frauscher B, Seppi K, et al. Modafinil for the treatment of daytime sleepiness in Parkinson's disease: a double-blind, randomized, crossover, placebo-controlled polygraphic trial. Sleep. 2002 Dec;25(8): 905-9.

88. Nieves AV, Lang AE. Treatment of excessive daytime sleepiness in patients with Parkinson's disease with modafinil. Clin Neuropharmacol. 2002 Mar-Apr;25(2):111-4.

89. Ondo WG, Fayle R, Atassi F, Jankovic J. Modafinil for daytime somnolence in Parkinson's disease: double blind, placebo controlled parallel trial. J Neurol Neurosurg Psychiatry. 2005 Dec;76(12):1636-9.

90. Talbot K, Stradling J, Crosby J, Hilton-Jones D. Reduction in excess daytime sleepiness by modafinil in patients with myotonic dystrophy. Neuromuscul Disord. 2003 Jun;13(5): 357-64.

91. Rammohan KW, Rosenberg JH, Lynn DJ, Blumenfeld AM, Pollak $\mathrm{CP}$, Nagaraja HN. Efficacy and safety of modafinil (Provigil) for the treatment of fatigue in multiple sclerosis: a two centre phase 2 study. J Neurol Neurosurg Psychiatry. 2002 Feb;72(2):179-83.

92. Zifko UA, Rupp M, Schwarz S, Zipko HT, Maida EM. Modafinil in treatment of fatigue in multiple sclerosis. Results of an openlabel study. J Neurol. 2002 Aug;249(8):983-7.

93. Pack AI, Black JE, Schwartz JR, Matheson JK. Modafinil as adjunct therapy for daytime sleepiness in obstructive sleep apnea. Am J Respir Crit Care Med. 2001 Nov 1;164(9):1675-81.

94. Czeisler CA, Walsh JK, Roth T, Hughes RJ, Wright KP, Kingsbury $\mathrm{L}$, et al. Modafinil for excessive sleepiness associated with shiftwork sleep disorder. N Engl J Med. 2005 Aug 4;353(5):476-86.

95. Harsh JR, Hayduk R, Rosenberg R, Wesnes KA, Walsh JK, Arora $S$, et al. The efficacy and safety of armodafinil as treatment for adults with excessive sleepiness associated with narcolepsy. Curr Med Res Opin. 2006 Apr;22(4):761-74.

96. U.S. Xyrem Multicenter Study Group. A randomized, double blind, placebo-controlled multicenter trial comparing the effects of three doses of orally administered sodium oxybate with placebo for the treatment of narcolepsy. Sleep. 2002 Feb 1;25(1):42-9.

97. U.S. Xyrem Multicenter Study Group. Sodium oxybate demonstrates long-term efficacy for the treatment of cataplexy in patients with narcolepsy. Sleep Med. 2004 Mar;5 (2):119-23.

98. Xyrem International Study Group. Further evidence supporting the use of sodium oxybate for the treatment of cataplexy: a doubleblind, placebo-controlled study in 228 patients. Sleep Med. 2005 Sep;6(5):415-21.

99. Black J, Houghton WC. Sodium oxybate improves excessive daytime sleepiness in narcolepsy. Sleep. 2006 Jul 1;29(7): 939-46.

100. Xyrem International Study Group. A double-blind, placebocontrolled study demonstrates sodium oxybate is effective for the treatment of excessive daytime sleepiness in narcolepsy. $\mathrm{J}$ Clin Sleep Med. 2005 Oct 15;1(4): 391-7.

101. Mamelak M, Black J, Montplaisir J, Ristanovic R. A pilot study on the effects of sodium oxybate on sleep architecture and daytime alertness in narcolepsy. Sleep. 2004 Nov 1;27(7):1327-34.

102. U.S. Xyrem Multicenter Study Group. A 12-month, open-label, multicenter extension trial of orally administered sodium oxybate for the treatment of narcolepsy. Sleep. 2003 Feb $1 ; 26(1): 31-5$.

103. van der Meche FG, Bogaard JM, van der Sluys JC, Schimsheimer RJ, Ververs CC, Busch HF. Daytime sleep in myotonic dystrophy is not caused by sleep apnoea. J Neurol Neurosurg Psychiatry. 1994 May;57(5):626-8.

104. Poppe M, Friebel D, Reuner U, Todt H, Koch R, Heubner G. The Kleine-Levin syndrome - effects of treatment with lithium. Neuropediatrics. 2003 Jun;34(3):113-9.

105. Deadwyler SA, Porrino L, Siegel JM, Hampson RE. Systemic and nasal delivery of orexin-A (Hypocretin-1) reduces the effects of sleep deprivation on cognitive performance in nonhuman primates. J Neurosci. 2007 Dec 26;27(52):14239-47. 